\title{
An Analysis of the English Translation of Li Bai's Poems
}

\section{Huang Shanshan ${ }^{1}$, Wang Feng ${ }^{2}$}

\author{
${ }^{1}$ School of Foreign Studies, Yangtze University, Hubei, 434023 PRC China \\ Email: 2476835606@qq.com \\ ${ }^{2}$ School of Foreign Studies, Yangtze University, Hubei, 434023 PRC China \\ Email:wangfeng@yangtzeu.edu.cn (correspondence)
}

\begin{abstract}
For more than 300 years, Li Bai's poems have been translated, introduced and disseminated in large quantities, which undoubtedly plays an important role in the out-going of Chinese culture. Based on the general historical context of the English translation of Li Bai's poems and the collected data about his translations, this study analyses the characteristics of his English translation in different periods and sums up how Li Bai's poems have claimed the world literary status.
\end{abstract}

Keywords-Li Bai's poems, English translation, characteristics, the world literary status.

\section{INTRODUCTION}

In recent years, scholars in China and other countries have become more and more enthusiastic about the translation of $\mathrm{Li}$ Bai's poems and have made some achievements. However, the research field is relatively isolated, mainly focusing on the translation theory or practice, lacking of comprehensive interdisciplinary research. Literary translation is not an isolated activity, which requires multidisciplinary cooperation to promote its dissemination and exchange. This study attempts to combine the translation and dissemination of Li Bai's poems in the English-speaking world, systematically review the translating process and summarize the successful factors in the translation and dissemination of Li Bai's poems. This will not only enrich the research on the English translation of Li Bai's poems, but also reveal something about the development of world literature.

1. A Summary of the Successful Translation of $\mathbf{L i}$ Bai's Poems in the English-speaking World

China has been a country of poetry since ancient times. Chinese classical poetry is not only the crystallization of the collective wisdom of the Chinese nation, but also a sparkling pearl in world literary history. With the promotion of translation media, many classical works represented by Tang poetry have been translated and introduced one after another. As one of the greatest masters of Tang poetry, Li Bai is remembered for his romance, sense of social responsibility and fresh and elegant poems. His poems are also gradually regarded as clas sics [37].

\section{II.}

\subsection{Before the 20th Century: the Initial Stage}

As early as the 18th century, there were sporadic records of the poet Li Bai in the West. Most of these records were made by missionaries, diplomats or sinologists. It is based on these early explorations that the translation and introduction of Li Bai's poems can be developed rapidly in the later stage. During this period, there appeared such representative figures as Herbert A. Giles, Joseph Edkins, W. A. P. Martin and John Francis. Among them, Giles was the first Western scholar who systematically translated Tang poetry as a monographic collection and introduced it to the world [23]. In his Chinese Poetry in English Verse (1898), he selected from 102 ancient Chinese poets and translated nearly 200 poems, of which 21 poems were written by $\mathrm{Li}$ Bai, occupying a considerable proportion [9].

2.2 From the 20th Century to the 1990s: the Flourishing Period

Since the beginning of the 20th century, the Imagist Movement in the West has attributed to the popularity of Sinology, which is embodied in the in itiative of the great poets headed by Ezra Pound to seek the commonality from Chinese classical poetry and provide nutrition and impetus for the American New Poetry Movement. For example, in his Cathay (1915) [17], there are 19 Chinese poems, including 12 poems by $\mathrm{Li}$ Bai, such as "The River-Merchant's Wife: a Letter”(长干行), “Taking Leave of a Friend”(送友人), and “The Jewel Stairs” Grievance”(玉阶怨). In addition, Amy Lowell's FirFlower Tablets was published in 1921, which contained nearly 150 Chinese poems, among which more than 80 poems were written by $\mathrm{Li}$ Bai [3]. Arthur Waley, a 
famous Sinologist of the same period, collected Li Bai's poems in his The Poet Li Po (1919) [21].

With the vigorous development of the English translation of Chinese poetry, Li Bai's poetry has attracted more attention of such scholars as W. J. B. Fletcher, Shigeyoshi Obata and Witter Bynner. In Fletcher's Gems of Chinese Verse (1919), there are 36 translations of Li Bai's poems [6]. In 1922, The Works of Li Po, the Chinese Poet, translated by a Japanese scholar, Shigeyoshi Obata, was published by E. P. Dutton \& Co., including $124 \mathrm{Li}$ Bai's poems [15]. It's the first collection of Li Bai's poems in English, which reflects the recognition of Li Bai's literary status in the Englishspeaking world and has great historical significance. Witter Bynner and Kiang Kanghu published The Jade Mountain Being Three Hundred Poems of the Tang Dynasty in 1929, including 27 poems by Li Bai [2]. In 1940 and 1944, Roger Soame Jenyns published Selection from the Three Hundred Poems of the T'ang Dynasty and A Further Selection from the Three Hundred Poems of the T'ang Dynasty, respectively collecting 11 poems and 9 poems written by Li Bai [26].

After World War II, the upsurge of translating Chinese poetry into English rose again in the English-speaking world. The study on the translation of Li Bai's poetry has shown a more diversified development. In addition to the translation of works, attention has also been paid to the analysis of works themselves and the study of the poet's life. In Waley's The Poetry and Career of Li Po (1950), quite a lot of Li Bai's poems are included, and his life and background are comprehensively described, which introduces the history of Tang Dynasty and Chinese culture to a great extent [22]. It can be regarded as the most important book about Li Bai's life in the English-speaking world. Since its publication in 1950, the book has been highly praised and reprinted continuously, which has greatly promoted the spread of Li Bai's poetry [8]. Arthur Cooper is the author of $\mathrm{Li} P o$ and $\mathrm{Tu} F u$ (1973), which contains many poems of Li Bai [4]. During this period, many other influential works have appeared such as The Great Age of Chinese Poetry: The High T'ang by Stephen Owen (1981) [16], Among the Flowers by L. Fusek (1982) [7] and New Songs from a Jade Terrace by A. Birrel (1982) [1]. Moreover, many large authoritative literary translation anthologies published in the English-speaking world during this period have included Li Bai's poems: The Columbia Book of Chinese Poetry (From Early Times to the Thirteenth Century) compiled by Burton Watson was published in 1984 [30]; The Indiana Companion to Traditional Chinese Literature (1986) [14] compiled by William H. Nienhauser Jr., has been an authoritative reference book during this period. It gives a special introduction to Li Bai's poems according to different classification standards. $\mathrm{Xu}$ Yuanchong, a Chinese translator, published Selected Poems of Li Bai (李白诗选) in 1987 [31], which was regarded by western scholars as "the most beautiful trans lation of ancient Chinese poetry", of which especially “Ballad of a Trader's Wife" (长干行) was highly praised in the West. Xu Zhongjie, a professor in many top universities in China published Two Hundred Chinese Tang Poems in English Verse in 1990, including 20 poems written by Li Bai [35]. Three Chinese Poets: Translations of Poems by Wang Wei, Li Bai, and Du Fu (1992) by the poet Vikram Seth has studied and analyzed Li Bai's life and the background of his times [18].

2.3 From the 21st Century to the Present: A New Period

The translation and introduction of Li Bai's poems from the initial exploration to the vigorous development of the 1990s have shown us the general context of how an excellent national literature attracts other nationalities to learn from and how it is promoted. In the 21 st century, the situation of the English translation of Li Bai's poems seems to be different from before: there are relatively fewer new translations. For example, during this period, only several authoritative works or anthologies of Chinese literature were published.

However, Chinese scholars have increased their participation in the translation of Li Bai's poems, which has contributed greatly to the poems' dissemination. Xu Yuanchong's Three Hundred Tang Poems (唐诗三百首) was published in 2000 [32]. Yang Xianyi and Gladys Yang compiled A Choice Selection of Ancient Poems (Chinese-English ): Tang Poems (古诗苑 汉英译丛：唐诗) (2001) [38]. Liu Junping compiled New Versions of Old Gems (2002) [13]. Wang Yushu published Wang 's Translation of 300 Tang poems in 2004 [28] as well as Selected Poems and Pictures of the Tang Dynasty in 2005 [29]. Tang Yihe's Three Hundred Tang Poems was published in 2005 [19]. Xu Yuanchong published Selected Poems of Li Bai in 2005 [33]. Gong Jinghao published A Bouquet of Poems from China's Tang Dynasty in 2006 [10]. Chinese Classical Poems with English Translations \& Comments was compiled by Liu Guoshan et al (2009) [12]. Zhuo Zhenying and Liu Xiaohua published An Anthology of Chinese Classical Poetry in 2010 [41]. A Critical Anthology of Tang Poetry and their English Translations, compiled by Wang Feng and Ma Yan, was published in 2011 [24]. Zhu Manhua published Chinese Famous Poetry Translated by Manfield Zhu in 2013 [40]. Selected Poems of Li Bai Translated by Xu Yuanchong (2014) is translated with the appreciation from Li Ming [34]. At the same time, some young scholars from universities in China have actively 
devoted themselves to the study of Li Bai's poetry translation: some of them have made a critical study on $\mathrm{Li}$ Bai's representative poetry translation based on the Harmony-guided Three-Level translation theory [36] [39]. Others, starting from cultural self-confidence and selective adaptation, rethink and interpret the English translation of Tang poetry represented by Li Bai [11] [27]. 2.4 The Characteristics of Translation in Different Periods

\subsubsection{The Initial Stage: Indirect Translation and Low} Accuracy

For religious and political reasons, the first people who translated Li Bai's poems were mainly missionaries, diplomats and sinologists. It is also because of the identities of these early translators that the relevant translation records of $\mathrm{Li}$ Bai's poems are sporadic. Looking at these records, it is not difficult to find that the greatest feature of translation at this time is mainly indirect translation. Li Bai's poems were first introduced to the Western world by a French Jesuit. In the 18th century, Britain lacked the ability to study China independently, but mainly through France. Le Livre de Jade (1867) translated by Judith Gantier, a French wo man writer, translator and critic, was the most popular French translation of classical Chinese poetry, including 19 of Li Bai's poems [23]. It is also due to the fact that translators often translate indirectly, the versions of the translated poems are not uniform, and the translators' personal style and creative elements are inevitably added to the translations, so the accuracy of translating poems is not high.

2.4.2 The Flourishing Period: Direct Translation and Cooperative Translation; Concise and Understandable Language

One of the major events in this period is the Imagist Movement led by Pound in the English-speaking world, which has triggered a wave of learning from Chinese classical poetry in the West, especially Li Bai's poems. During this period, the translator's identity has become more diverse. There are missionaries, diplomats, poets, translators, critics, sinologists and so on. In addition, as far as the ways of translation are concerned, besides indirect translation, direct translation and cooperative translation are increasing. In terms of translation styles, translators tend to use concise and understandable language to translate and introduce Li Bai's poems. For example, Pound translated 12 poems of Li Bai in Cathay. The language he used was "the simplest in all his translations and the least influenced by ancient language" [20]. In addition to the poetry text, the study on the poet Li Bai himself has been greatly developed in this period. As mentioned above, in Waley's The Poetry and Career of Li Po, there are comprehensive descriptions of Li Bai's life and historical background as well as in the poet Vikram Seth's Three Chinese Poets: Translations of Poems by Wang Wei, Li Bai, and Du Fu. Furthermo re, Li Bai's poems were included in many large authoritative literary translation anthologies published in the Englishspeaking world at that time. For example, The Columbia Book of Chinese Poetry: From Early Times to the Thirteenth Century was compiled and published by Burton Watson in 1984. The Indiana Companion to Traditional Chinese Literature (1986), compiled by William H. Nienhauser Jr., was an authoritative reference book during that period.

\subsubsection{A New Period: Chinese Translators' Contributions}

Compared with the previous two periods, in the context of the new era, translators in the English-speaking world have fewer new translations of Li Bai's poems, while Chinese translators have made great contributions to the translation and introduction of Li Bai's poems. First of all, among the few foreign translations, there are several authoritative works or anthologies of Chinese literature published in the English-speaking world: The New Directions Anthology of Classical Chinese Poetry (2003) compiled by Eliot Weinberger; the Cambridge History of Chinese Literature (Vol. 1), co-edited by Kang-I Sun Chang and Stephen Owen (2010). Secondly, after thoroughly reading the English translations of foreign translators, Chinese translators have carried out relevant reflections and research reviews, and thus have devoted themselves to the re-translations of Tang poetry represented by Li Bai's poems, such as the group of Chinese translators headed by $\mathrm{Xu}$ Yuanchong, Yang Xianyi, Sun Dayu and Wang Yushu, which are gradually recognized by the world.

\section{THE CLAIMING OF WORLD LITERARY STATUS OF LI BAI'S POEMS}

According to David Damrosch, world literature is the elliptical refraction of national literature, the result of translation, and a way of transcendental interpretation of the distant space-time world, rather than a set of classical texts [5]. And he repeatedly emphasized that world literature is always related to both the value and demand of the host culture and the source culture, which is a process of double refraction... Any world literary text is closely related to these two different cultures, not decided by either side alone [5]. Therefore, we can understand the inevitability of Li Bai's poetry moving towards world literature in the process of English translation. Has $\mathrm{Li}$ Bai's poetry become world literature? Wang Ning holds that five principles must be followed in judging whether a literary work belongs to world literature: (1) whether it grasps the spirit of the times; (2) whether its influence 
exceeds the boundaries of its own country/nation or national language; (3) whether it is included in the anthology of literary classics compiled by later researchers; (4) whether it can enter the university classroom; and (5) whether it is criticized in another context [25]. Lived in the prosperous Tang Dynasty, Li Bai's powerful style and romantic feelings all reflected the humanistic style of the prosperous Tang Dynasty when many scholars were eager to make contributions, and $\mathrm{Li}$ Bai was no exception. He wrote his ideals and aspirations into his poems and spoke for himself and other aspiring people. Later, when his hopes failed, he sought solace in drinking, leaving a good impression of being free and easy. Although his career was bumpy, he was deeply concerned with society, so there were many descriptions of the images of the people at the bottom of society in his poems, such as his frontier fortress poems and boudoir-plaint poems, which expressed the misery of people's life and criticized the political situation of corruption. It can be said that Li Bai's poetry was the epitome of the society at that time. Since the initial translation of Li Bai's poems, Li Bai's poems have gone out of China and influenced other nations in the world. According to the statistics above, during the flourishing period, many large authoritative literary anthologies published in the English-speaking world included the English translations of Li Bai's poems; in the new period, there are also several authoritative English or bilingual literary works or anthologies which are often used as university textbooks. From the early stage to the flourishing stage of the English translation of Li Bai's poems, translators in the English-speaking world have made great contributions and published many excellent translations. In the new era, Chinese translators have found relevant problems in these previous translations, thus launching a critical study to push the translation of $\mathrm{Li}$ Bai's poems to a climax again, and enabling the world to have a more comprehensive understanding of Li Bai's poems.

\section{CONCLUSION}

The successful translation and introduction of Li Bai's poems is the result of joint efforts. First of all, the artistic achievements of Li Bai's poetry are worthy of affirmation, and its influence transcends the boundaries of its own nation. Learners from other nationalities can draw nutrition from it, so translators are very active in translating, introducing and disseminating Li Bai's poems, which is reflected in the collection of Li Bai's poems in many authoritative books and the university textbooks. At the same time, Chinese scholars have been actively exploring and reflecting on the translation and introduction of Li Bai's poems in the English-speaking world, further promoting the external dissemination of $\mathrm{Li}$ Bai's poetry from a new perspective, and creating opportunities for more excellent traditional Chinese culture to be well known in various languages and cultures.

\section{ACKNOWLEDGEMENT}

This work was supported by the Ministry of Education Hu manities and Social Sciences 2015 Youth Fund under Grant [15YJC740078]; the National Social Science Fund of China under Grant [Key Project 17AZD040].

\section{REFERENCES}

[1] Birrell, Anne (trans.). New Songs from a Jade Terrace: An Anthology of Early Chinese Love Poetry. London: George Allen \& Unwin, 1982.

[2] Bynner, Witter and Kiang Kang-hu. (trans.). The Jade Mountain: A Chinese Anthology, Being Three Hundred Poems of the T'ang Dynasty, 618-906. New York: Knopf, 1929.

[3] Chen, Huaizhi. The Translation, Dissemination and Impact of Li Bai's Poems in the United States. Journal of Xichang College (Social Sciences Edition), 2013, 25 (03): 21-24.

[4] Cooper, Arthur. Li Po and Tu Fu. Harmondsworth: Penguin Books Ltd., 1973.

[5] Damrosch, D. What is World Literature?. Princeton: Princeton University Press, 2003.

[6] Fletcher, W.J.B. (trans.). Gems of Chinese Verse. Shan ghai: The Commercial Press, 1919.

[7] Fusek, Lois (trans.). Among the Flowers: the Hua-chien chi. Columbia University Press, 1982.

[8] Gao, Hong, Zhan Xiaojuan. Translation of Li Bai's Poetry in Britain and its Characteristics. Journal of Mianyang Normal University, 2015, 34 (12): 18-23.

[9] Giles, Herbert Allen. Chinese Poetry in English Verse. B. Quaritch, 1898.

[10] Gong, Jinghao (trans.). A Bouquet of Poems from China's Tang Dynasty. Beijing: Commercial Press. 2006.

[11] Huang, Shanshan, Wang Feng. On the English Translation of Culture-loaded Words in Qiang Jin Jiu. Journal of Humanities and Education Development (JHED) Vol-1, Issue-3, May-Jun 2019.

[12] Liu, Guoshan et al (trans.). Chinese Classical Poems with English Translations \& Comments. Beijing: Foreign Language Press. 2009.

[13] Liu, Junping (trans.). New Versions of Old Gems. Beijing: Zhonghua Publishing House. 2002.

[14] Nienhauser, William H. The Indiana Companion to Traditional Chinese Literature. Indiana University Press, 1986.

[15] Obata, Shigey oshi. The Works of Li Po, New York: Dutton, 1922.

[16] Owen, Stephen. The Great Age of Chinese Poetry: The High T'ang. New Haven: Yale University Press, 1981.

[17] Pound, Ezra. Cathay. London: Elkin Mathews, 1915. 
[18] Seth, Vikram. Three Chinese Poets: Translations of Poems by Wang Wei, Li Bai and Du Fu, London: Faber, and New York: Harper, 1992.

[19] Tang, Yihe (trans.). Three Hundred Tang Poems. Tianjin: Tianjin People's Publishing House. 2005.

[20] Twitcher, Jeff, Zhang Ziqing. Pound's Cathay and Imagist Poetry. Foreign Literature Review, 1992 (01): 86-91.

[21] Waley, Arthur. The Poet Li Po, AD 701-762. East and West, Limited, 1919.

[22] Waley, Arthur. The Poetry and Career of Li Po, 701 -762 $A D$. London: Allen and Unwin, 1950.

[23] Wang, Feng. A Comprehensive Study on the English Translation of Classical Tang Poetry. Beijing: China Social Sciences Press, 2015.

[24] Wang, Feng, Ma Yan. A Critical Anthology of Tang Poetry and their English Translations. Xi'an: Shanxi People's Publishing House, 2011.

[25] Wang, Ning. "World Literature": From Utopian Imagination to Aesthetic Reality. Exploration and Controversy, 2010 (07): 3-9+83.

[26] Wang, Wei. Li Bai's Research Towards the World. Literary Heritage, 2002 (03): 131-137.

[27] Wang, Xu, Wang Feng, and Zeng Yan. The English Translation of Tang Poetry Based on Cultural Selfconfidence and Selective Adaptation-Taking "Changgan Xing" as an Example. English Literature and Language Review, Vol. 5, Issue. 6, pp: 75-81, 2019.

[28] Wang, Yushu (trans.). Wang's Translation of 300 Tang poems. Beijing: Wuzhou Communication Publishing House. 2004.

[29] Wang, Yushu (trans.). Selected Poems and Pictures of the Tang Dynasty. Beijing: Wuzhou Communication Publishing House, 2005.

[30] Watson, Burton. The Columbia Book of Chinese Poetry (from Early Times to the Thirteenth Century). New York: Columbia University Press, 1984.

[31] Xu, Yuanchong (trans.). Selected Poems of Li Bai. Chengdu: Sichuan People's Publishing House, 1987.10.

[32] Xu, Yuanchong (trans.). Three Hundred Tang Poems. Beijing: Higher Education Press, 2000.08.

[33] Xu, Yuanchong (trans.). Selected Poems of Li Bai. Hebei People's Publishing House, 2005.

[34] Xu, Yuanchong (trans.). Selected Poems of Li Bai Translated by $\mathrm{Xu}$ Yuanchong. Beijing: China Foreign Translation and Publishing Co., Ltd. 2014.

[35] Xu, Zhongie (trans.). Two Hundred Chinese Tang Poems in English Verse. Beijing: Beijing Lan guage Institute Press, 1990.01.

[36] Yan, Qian, Wang Feng. On the Translation of "Drinking Alone under the Moon" Based on the Harmony-Guided Criteria for Poetry Translation. IRA-International Journal of Education \& Multidisciplinary Studies, 2019, (1):5-13.

[37] Yang, Kai. Translation and Canonization of Li Bai's Poems in the English-speaking World. Journal of the College of Literature, Nanjing Normal University, 2017 (03): 100-104.

[38] Yang, Xianyi, Yang Gladys (trans.). A Choice Selection of Ancient Poems (Chinese-English ): Tang Poems. Beijing: Foreign Language Publishing House, 2001.
[39] Yin, Rongrong, Wang Feng. A Study of English Translation of Li Bai's "Gu Lang Yue Xing" Based on the Harmony-Guided Criteria for Poetry Translation. Translation and Cultural Studies, 2019 (6).

[40] Zhu, Manhua (trans.). Chinese Famous Poetry Translated by Manfield Zhu. Beijing: Business Press International Co., Ltd. 2013.

[41] Zhuo, Zhenying, Liu Xiaohua (trans.). An Anthology of Chinese Classical Poetry. Guangzhou: Jinan University Press, 2010. 